controls. These findings could account for the nature of our patients' response to hypercalcaemia. Our patients' calcitonin production in response to hypercalcaemia need not exceed that of the normal to achieve the prompt control of hypercalcaemia seen. Whether or not calcitonin production is actually greater than normal in hyperthyroidism needs to be confirmed by assay of the hormone itself.

Our finding of increased retention of calcium load is consistent with the greater-than-normal rate of bone accretion in hyperthyroidism in the presence of induced hypercalcaemia. Clerkin et al. (1964) also found increased calcium retention in hyperthyroid patients, but they interpreted this to indicate the presence of osteomalacia. It is true that in osteomalacia, where there is inadequate mineralization of bone due to calcium deficiency, an avid uptake of calcium by bone following an infused calcium load could itself influence the rate of return of serum calcium to its initial level. There is, however, abundant evidence that the bone changes in hyperthyroidism are not those of osteomalacia (Osterberg and Mills, 1932 ; Jowsey, 1966 ; Adams et al., 1967). This is supported by results of tracer stadies by Krane et al. (1956) and Eisenberg and Gordan (1961).

The results of this study suggest that in bone disease in which increased bone resorption exceeds increased bone accretion, such as hyperthyroid osteoporosis (Krane et al., 1956; Eisenberg and Gordan, 1961 ; Jowsey, 1966 ; Adams and Jowsey, 1967), Paget's disease (Nagant de Deuxchaisnes and Krane, 1964 ; Jowsey, 1966), and acromegaly (Eisenberg and Gordan, 1961), calcium infusion might be a useful therapeutic measure. By indirectly inhibiting the prevailing increased bone resorption in the presence of increased bone accretion, calcium infusion greatly enhances net bone accretion as our results suggest, and may lead to healing of bone itself. Moreover, hypercalcaemia induced by calcium infusion in these circumstances, as shown by our results, is relatively mild and shortlived-a cecided advantage. This would not be so if bone accretion rate is normal in the presence of increased bone resorption as in postmenopausal and senile osteoporosis (Lafferty et al., 1964), in which hypercalcaemia would be expected to be as prolonged as in the normal. If shown to be effective and safe, calcium infusion would present a significant advance in the treatment of those bone diseases in which kinetic studies indicate high turnover rate with increased bone resorption exceeding increased bone accretion.

\section{REFERENCES}

Adams, P. H., and Jowsey, J. (1967). Endocrinology, 81, 735.

Adams, P. H., et al. (1967). Quarterly fournal of Medicine, 36, 1.

Aliapoulios, M. A.., Goldhaber, P., and Munson, P. L. (1966). Soience, $151,330$.

Aub, J. C., Abright, F., Bauer, W., and Rossmeisl, E. (1932). Fournal of Clinical Investigation, 11, $21 i$.

Bijvoet, O. L. M., van der Sluys Veer, J., and Jansen, A. P. (1968) Lancet, 1, 876.

Clerkin, E. P., Haas, H. G. Mintz, D. H., Meloni, C. R., and Canary, J. J. (1964). Metabolism, 13, 161.

Cope, O., and Donaldson, G. A. (1937). Foumal of Clinical Investigation, 16, 329.

Eisenberg, E., and Gordan, G. S. (1961). Fournal of Clinical Investiga-

tion, 40, 1809.
Epstein, F. H., Freedman, L. R., and Levitin, H. (1958). New England Fournal of Medicine, 258, 782.

Foster, G. V. (1968). Postgraduate Medical foumal, 44, 411.

Frizel, D., Malleson, A., and Marks, V. (1967). Lancet, 1, 1360.

Gudmundsson, T. V., et al. (1969). Lancet, 1, 443.

Jowsey, J. (1.966). American fournal of Medicine, 40, 485.

Kleeman, C. R., Tuttle, S., and Bassett, S. H. (1958). Fournal of Clinica Endocrinology and Metabolism, 18, 477.

Krane, S. M., Brownell, G. L., Stanbury, J. B., and Corrigan, H. (1956). fournal of Clinical Investigation, 35, 874.

Lafferty, F. W., Spencer, G. E., and Pearson, O. H. (1964). In Dynamic Studies of Metabolic Bone Disease, edited by O. H. Pearson and G. F. Joplin, p. 101. Oxford, Blackwell.

Mittleman, R., Chausmer, A., Bellavia, J., and Wallach, S. (1967). Endocrinology, 81, 599.

Nagant de Deuxchaisnes, C., and Krane, S. M. (1964). Medicine, 43, 233.

Osterberg, A. E., and Mills, R. G. (1932). American fournal of Medical Sciences, 184, 399.

Sturtridge, W. C., and Kumar, M. A. (1968). Lancet, 1, 725.

\title{
Maintenance of Silastic-Teflon Shunts for Intermittent Haemodialysis
}

\author{
C. S. MCINTOSH,* M.B., CH.B.; J. C. PETRIE, $\dagger$ M.B., M.R.C.P. ; M. MACLEOD, $\ddagger$ M.D., F.R.C.P.ED.
}

\begin{abstract}
Summary: The occurrence of infection in the tissues $D$ surrounding external arteriovenous shunts was studied and the important relationship of pyogenic infection to clotting was confirmed. The local application of fusidic acid tulle and lanolin greatly reduced the occurrence of both infection and clotting and the need for cannula replacement.

Urokinase used for declotting shunts when standard procedures had failed, restored blood flow whether clotting was related to infection or to local vascular factors. This treatment is not advised when clotting is associated with a local abscess, as it may make cannula replacement necessary. Severe local vascular factors, such as metastatic calcification, Raynaud's phenomenon, and venous stenosis, may lead to poor blood flow, so that despite clot lysis elective cannula replacement or the creation of a subcutaneous arteriovenous fistula is required.
\end{abstract}

* Medical Registrar, Aberdeen General Hospitals.

t Lecturer in Therapeutics, University of Aberdeen.

¥ Reader in Medicine, Department of Medicine, University of Aberdeen.

\section{Introduetion}

Intermittent haemodialysis is a comparatively straightforward procedure when undertaken with suitable facilities after adequate training. The commonest problems are concerned with the external Silastic-Teflon shunt (Pendras and Smith, 1966). Patients are discouraged and heavy deraands made on the staff by recurring local infection (Martin et al., 1967), repeated clotting (Wing et al., 1967), and frequent replacement of the shunt (Ramirez et al., 1966). Many units are therefore turning to subcutaneous arteriovenous fistulae (Brescia et al., 1966), despite their drawbacks for some patients who are dialysed at home.

In this paper we report the effect of a number of simple procedures on the reduction of pyogenic infection and clotting and the value of urokinase in declotting cannulae by fibrinolysis.

\section{Patients and Methods}

Ten patients with irreversible renal failure were studied over a period of 128 patient-months. Six patients were fully and 
two were partially rehabilitated. Two died four months after starting treatment. Patients attended the hospital unit overnight from distances of up to 70 miles $(112 \mathrm{~km}$.) for a total of 28 to 36 hours' dialysis each week. All technical procedures were carried out by nurses under medical supervision. Dialysing fluid was supplied to Kiil dialysers by gravity from tanks or by individual proportionating units.

Silastic-Teflon cannulae were inserted in forearm vessels in an operating-theatre by a surgeon with special experience in vascular surgery. The theatre dressing was not disturbed for at least seven days. Swabs were taken for culture from the skin area adjacent to the arterial and venous limbs of the shunt immediately before each dialysis.

During the first period, months 1 to 9 , the skin area was cleaned with normal saline and a 1 in 100 solution of Savlon. After dialysis a dry gauze dressing placed over the area was covered by an occluding crêpe bandage and left undisturbed until the next visit.

In the second period, months 10 to 20 , saline and antiseptic solutions were not used. A liberal quantity of lanolin (hydrous wool fat B.P.) was applied to the exit sites of the shunt after each dialysis. When infection was suspected clinically, or when a positive culture of Staphylococcus pyogenes was obtained, $2 \%$ fusidic acid ointment on tulle was applied in place of lanolin and wrapped closely round the Silastic inserts. Oral antibiotics, indicated by the sensitivity of the main organisms, were given during both periods. No antibiotics were administered parenterally.

All patents were given warfarin sodium as anticoagulant. The prothrombin time was estimated on the unit before each dialysis. An E.E.L. prothrombin meter was used and the ratio kept above 2.

Patients reported to the haemodialysis unit for declotting of their shunt under sterile conditions by the medical staff of the unit. If satisfactory flow. was not established by standard methods after about 15 minutes, urokinase was used for clot lysis. An ampoule of highly purified sterile urokinase containing 5,000 Ploug units was made up to $2 \mathrm{ml}$. with sterile water. All the solutions used were heated to $37^{\circ} \mathrm{C}$. The Silastic tube distal to the clot was washed out gently with $3.8 \%$ sodium citrate solution through a flexible catheter and subsequently emptied. Urokinase solution was then instilled through the catheter to the site of the clot, the tube clamped, and the solution left in position for at least two hours. After this time fragments of clot were removed by gentle suction. Excessive suction was unrewarding. If flow was insufficient the procedure was repeated. Stronger solutions may be used by dissolving the contents of an ampoule containing 25,000 units of urokinase in $5 \mathrm{ml}$. of sterile water.

\section{Results}

Infection. - The pattern of infection around the shunt in the two periods is shown in Table I. Only a moderate or heavy growth on culture is recorded. The occurrence of pyogenic infection in the two periods fell from $6.9 \%$ to $2.1 \%(P<0.001)$.

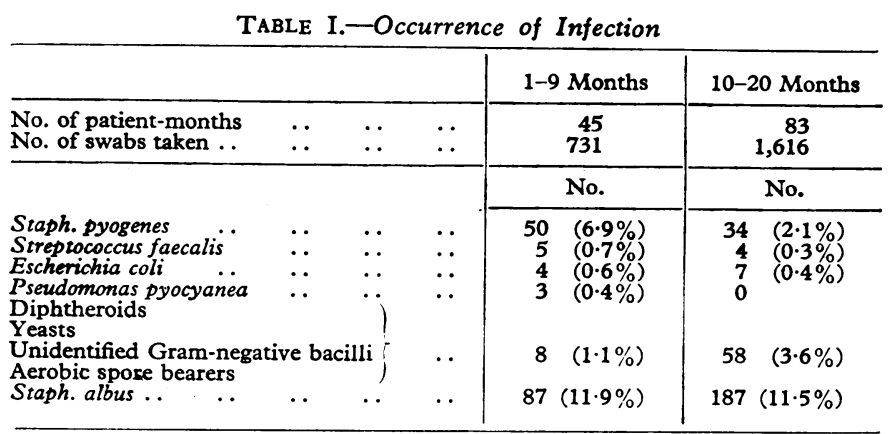

This reduction coincided with the local application of fusidic acid tulle and lanolin. There was an increase from $1.1 \%$ to $3.6 \%$ in positive cultures of diphtheroids, yeasts, unidentified Gram-negative bacilli, and aerobic spore bearers. There was no change in the percentage of swabs from which Staph. albus was grown.

Clot Episodes.-Clotting of a shunt, once or repeatedly in the course of a week, was regarded as a single clot episode. In the first period of 45 patient-months there were 25 such episodes. Nineteen of these were associated with local infection-in 16 this was due to Staph. pyogenes and in three to other organisms. In the second period of 83 patient-months only two clot episodes were associated with infection. In both instances Staph. pyogenes was cultured (Table II). Vascular factors were associated with clot episodes on six occasions in the first period and nine in the second. The vascular changes included poor venous calibre, venous stenosis, fibrin deposition at the tip of the Teflon insert and on the intimal surface, venous stenosis, severe Raynaud's phenomenon, and extensive calcification of the vascular tree (Fig.). These changes caused recurring problems with two patients.

\begin{tabular}{c|c|c|c|c}
\multicolumn{4}{c}{ TABLE II.-Clot Episodes } \\
\hline \multirow{3}{*}{ Months } & \multicolumn{2}{|c|}{ Clotting with Infection } & $\begin{array}{c}\text { Clotting } \\
\text { with } \\
\text { Vascular } \\
\text { Changes }\end{array}$ & Total \\
\cline { 2 - 4 } & $\begin{array}{c}\text { Staph. } \\
\text { pyogenes }\end{array}$ & $\begin{array}{c}\text { Other } \\
\text { Organisms }\end{array}$ & $\begin{array}{c}6 \\
9\end{array}$ & 25 \\
\hline $10-9$ & 16 & 3 & 11 \\
\hline
\end{tabular}

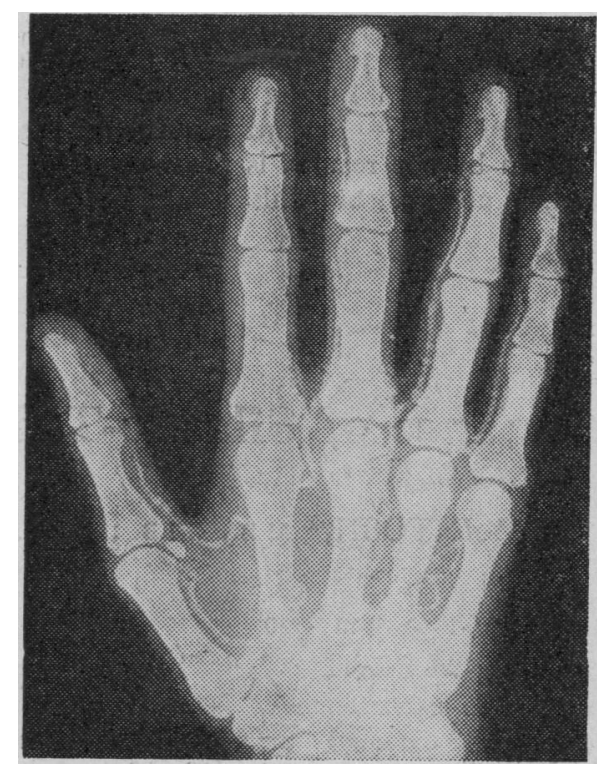

Extensive calcification of the peripheral vascular tree.

Declotting with Urokinase.-The results obtained when urokinase was used for clot lysis are shown in Table III. Though clot lysis occurred on every occasion on which urokinase was used, the procedure was considered to be successful only if full flow was established and maintained for seven days after its use. When standard procedures failed to declot a cannula urokinase was successful in re-establishing full flow for not less than a week in 21 out of 36 clot episodes. The mean prolongation of cannula survival was 2.5 months.

\begin{tabular}{|c|c|c|c|c|}
\hline & & & With Infection & $\begin{array}{l}\text { With Vascular } \\
\text { Changes }\end{array}$ \\
\hline $\begin{array}{l}\text { Clot episodes } \\
\text { Full flow restored } \ldots \\
\text { Cannula replacement }\end{array}$ & $\begin{array}{l}\cdots \\
\cdots\end{array}$ & $\begin{array}{l}\cdots \\
\because \\
\cdots\end{array}$ & $\begin{array}{r}21 \\
12 \\
9\end{array}$ & $\begin{array}{r}15 \\
9 \\
6\end{array}$ \\
\hline
\end{tabular}


Replacement of Cannulae.-Cannulae were replaced because of infection, local vascular factors, and skin erosion. The nine occasions on which a cannula was replaced when clotting was associated with infection were due to local abscess, oozing of blood, instability of the Teflon insert, or to repeated clotting within hours or days of blood flow being re-established. Local vascular factors, especially calcification and severe spasm, led to repeated clotting and replacement of the cannula on six occasions. Five further cannulae were electively replaced without preceding clotting. In the first period three cannulae were associated with local abscess formation, and Staph. pyogenes was cultured on all occasions. Two cannulae were replaced following skin erosion without infection.

\section{Discussion}

Almost all the problems due to infection of shunts were produced by Staph. pyogenes. Martin et al. (1967) have shown by phage typing that infection is often due to the patient's own flora. Occasionally Streptococcus faecalis, Escherichia coli, or Pseudomonas pyocyanea was associated with prominent local infection. Though Staph. albus was the commonest organism found on culture it was not associated with clinical evidence of infection. This was also the case with diphtheroids, yeasts, Gram-negative bacilli, and aerobic spore bearers. Fusidic acid, which was used locally when a positive culture of Staph. pyogenes was obtained, is bactericidal to most strains of staphylococci (Barber and Waterworth, 1962), and though resistance can be induced in vitro (Evans and Waterworth 1966 ) it is uncommon in clinical practice (Taylor and Bloor, 1962 ; Crosbie, 1963). Repeated applications of this agent on tulle during 83 patient-months did not produce a local reaction. With its use a great reduction in the occurrence of infection with Staph. pyogenes occurred, though yeasts, diphtheroids, and unidentified Gram-negative organisms were more frequently grown. During the second period lanolin was applied liberally to the area of the shunt (Kopp et al., 1967), when fusidic acid was not indicated. This appeared to have some protective effect in reducing maceration of the skin by cleansing solutions and antiseptics.

Throughout the first period of this study pyogenic infection of a shunt was often followed by clotting. Infection and clotting have been associated in some reports (Pendras and Smith, 1966 ; Martin et al., 1967), though this is less evident in others (Curtis et al., 1969). We found the reduction in the incidence of infection in the second period to be attended by a striking fall in clot episodes. Some reduction in clotting may occur because of increased technical experience and the beneficial effects of dialysis. Throughout both periods, however, there were frequent changes in the nursing and junior medical staff and new patients were being added to the programme. Antibiotic and anticoagulant treatment were similar. Control of pyogenic infection by local measures appeared to have an important effect on the reduction of recurrent clotting and the need for cannula replacement.

Clotting associated with venous stenosis occurred in four patients and was preceded by a gradual rise above normal venous pressure on the monitor during dialysis. An accurate method of making estimations of venous blood flow would indicate progressive stenosis and the need for elective change of a cannula before clotting occurred. Non-specific thrombophlebitis also preceded clot episodes. In this circumstance the use of contrast media for venography is seldom essential and may be contraindicated, as local intimal damage may be aggravated by their use. The commonly used material, $45 \%$ Hypaque, has an osmotic activity of over $1,000 \mathrm{mOsm} / 1$., which is comparable to a solution of glucose in excess of $20 \%$. One patient with polycystic disease had veins of very poor calibre in all limbs and severe Raynaud's phenomenon. Subcutaneous arteriovenous fistulae repeatedly clotted within 24 hours of their formation. Another patient, who was not unduly hyperphosphataemic, developed severe metastatic calcification almost confined to the vascular system. Its progress was not influenced by aluminium hydroxide orally or increased dialysis time, and superficial areas of gangrene developed on the extremities. These two patients accounted for 8 of the 11 clotting episodes in the second period.

The value of anticoagulants in reducing clot episodes has been reported (Wing et al., 1967). Control of anticoagulant dosage has special problems in these patients. The prothrombin time should be estimated before dialysis, as heparin increases the one-stage prothrombin time (Moser and Hajiar, 1967). Close control is important, so that comparatively small adjustments in dosage are required. The omission of or large reduction in one day's dose was followed by an extreme fall in prothrombin ratio, which may precipitate clotting. Facilities for estimating the prothrombin time on the unit at each attendance for dialysis were of great value.

As the maintenance of shunts presents the principal recurring problem in intermittent haemodialysis, the arrangements for declotting should be optimal. It should be carried out as early as possible under aseptic conditions in the unit by the medical staff. It is most important that all manipulations are gentle and all solutions used are at $37^{\circ} \mathrm{C}$. When full flow was not re-established by standard declotting procedures the use of a fibrinolytic activator was of great value. Urokinase is a naturally occurring activator which is not antigenic. It was used repeatedly without ill effects, including one patient who previously had shown pronounced hypersensitivity to streptokinase. The antigenicity of streptokinase is well documented (Fletcher et al., 1959 ; Anderson et al., 1967). Normally the therapeutic use of these potent agents must be controlled biochemically. In declotting shunts very small amounts enter the circulation. We have not found a significant effect on the plasma concentration of fibrinogen or plasminogen, or on the euglobulin clot lysis time after declotting with urokinase in the dosage used. In chronic renal failure the plasma fibrinogen levels are increased and fibrinolytic activity in tissue extracts and body fluids is diminished (MacLeod et al., 1962 ; Edward et al., 1964).

The great value of urokinase is demonstrated in re-establishing full flow in clotted shunts associated either with infection or with local vascular change. Cannula flow was restored with urokinase on every occasion on which it was used. The expense of urokinase was justified by a mean prolongation of cannula survival of 2.5 months. Local abscess is a contraindication, as continued oozing of blood from granulations following clot lysis will usually make it necessary to replace the cannula. This was also indicated when blood flow was limited or continual clotting occurred as a result of severe vascular change.

We acknowledge with gratitude the close collaboration of Professor George Smith, department of surgery, who established the external shunts and subcutaneous arteriovenous fistulae in these patients, and of the staff of the departmeni of bacteriology, University of Aberdeen.

Financial support for part of this work was received from the Scottish Hospital Endowments Research Trust.

Requests for reprints should be sent to Dr. M. Macleod, Department of Medicine, Foresterhill, Abredeen AB9 2ZD.

\section{REFERENCES}

Anderson, D. C., Martin, A. M., Clunie, G. J. A., Stewart, W. K., and Robson, J. S. (1967). In Dialysis and Renal Transplentation: Proceedings of the 4th Conference of the European Dialysis and Transplant Association, edited by D. N. S. Kerr, p. 55. Amsterdam, Excerpta Medica.

Barber, M., and Waterworth, P. (1962). Lancet, 1, 931.

Brescia, M. J., Cimino, J. E,. Appel, K., and Hurwich, B. J. (1966). New England fournal of Medicine, 275, 1089. 
Crosbie, R. B. (1963). British Medical fournal, 1, 788.

Curtis, J. R., et al. (1969). Quarterly fournal of Medicine, 38, 49.

Edward, N., Young, D. P. G., and MacLeod, M. (1964). Fournal of Clinical Pathology, 17, 365 .

Evans, R. J., and Waterworth, P. M. (1966). Fournal of Clinical Patho$\log y, 19,555$.

Fletcher, A. P., Alkjaersig, N., and Sherry, S. (1959). fournal of Clinical Investigation, 38, 1096.

Kopp, K. F., Grossmann, D. F., and Frey, J. (1967). In Dialysis and Transplantation: Proceedings of the 4th Conference of the European Dialysis and Transplant Association, edited by D. N. S. Kerr, p. 373. Amsterdam, Excerpta Medica.

MacLeod, M., Stalker, A. L., and Ogston, D. (1962). Lancet, 1, 191.
Martin, A. M., Clunie, G. J. A., Tonkin, R. W., and Robson, J. S. (1967). In Dialysis and Transplantation: Proceedings of the 4th Conference of the European Dialysis and Transplant Association, edited by D. N. S. Kerr, p. 67. Amsterdam, Excerpta Medica.

Moser, K. M., and Hajiar, G. C. (1967). Annals of Internal Medicine, 66, 1207.

Pendras, J. P., and Smith, M. P. (1966). Transactions of the American Society for Artificial Internal Organs, 12, 222.

Ramirez, O., Swartz, C., Onesti, G., Mailloux, L., and Brest, A. N. (1966). Transactions of the American Society for Artificial Internal Organs, 12, 220.

Taylor, G., and Bloor, K. (1962). Lancet, 1, 935.

Wing, A. J., Curtio, J. R., and de Wardener, H. E. (1967). British Medical fournal, 3, 143 .

\title{
Comparison of Depot Tetracosactrin and Corticotrophin Gel
}

\author{
B. L. J. TREADWELL,* M.B., M.R.A.C.P., M.R.C.P.ED.; P. M. DENNIS, $\dagger$ M.B., F.R.A.C.P., M.R.C.PATH.
}

British Medical fournal, 1969, 4, 720-723

Cummary : Depot tetracosactrin has been compared with $\checkmark$ corticotrophin gel in 12 inpatients of a rheumatic diseases unit. Every patient received one subcutaneous injection each of the synthetic and the animal preparation, with serial measurements of plasma 11-hydroxycorticosteroids, 12-hourly urinary 11-hydroxycorticosteroids, and 17-oxogenic steroids. The duration of action of the depot tetracosactrin was virtually twice that of corticotrophin gel, the dose relationship being about $0.25 \mathrm{mg}$. of depot tetracosactrin to 50 units of gel. Local reaction to the injection of depot tetracosactrin was relatively frequent.

\section{Introduction}

The first report of synthetic polypeptides with corticotrophinreleasing activity came from Kappeler and Schwyzer (1960). Subsequently these authors (1961) described the preparation of a synthetic polypeptide (Synacthen) in crystalline form which was highly soluble in water and rapidly absorbed after intramuscular injection. Landon et al. (1964) showed that infused Synacthen (tetracosactrin) increased both plasma cortisol levels and urinary 17-ketosteroids and 17-hydroxycorticosteroids (17-OHCS). The synthetic preparation caused no sensitivity reaction in two patients sensitive to animal corticotrophin. Tetracosactrin consists of the first 24 amino-acids found in the 39 amino-acid chain of animal corticotrophin. It has a high degree of activity lasting one and a half to three hours by intramuscular injection. Since 19.67 a long-acting preparation of

* Rheumatologist, Wellington Hospital, Wellington, New Zealand.

† Chemical Pathologist, Prince Henry's Hospital, Melbourne, Victoria, Australia. tetracosactrin adsorbed on to an inorganic zinc complex has been on trial. Besser et al. (1967) and Nelson et al. (1968) reported the effect of depot tetracosactrin on plasma 11-hydroxycorticosteroids (11-OHCS). We describe here our experience of this substance with both plasma and urinary steroids as criteria, our aim being to assess biochemical and clinical effects in comparison with corticotrophin gel.

\section{Patients and Methods}

There were 12 subjects, 11 with rheumatoid disease and 1 with gout. All were hospital inpatients with clinical disease activity, so that therapeutic observations were possible. No patient had ever previously been treated with corticosteroids or corticotrophin. In every case the proposed investigation was fully explained to the patients, their approval to proceed being obtained. Administration of depot tetracosactrin and corticotrophin gel was subcutaneously, as this is the only feasible route for self-administration should long-term therapy be required.

Studies in each case covered six days with 12-hourly urine collections from 9 a.m. to 9 p.m. and from 9 p.m. to 9 a.m. throughout. Corticotrophin was administered at 9 a.m. on Day 2 and Day 5, every patient receiving one dose of depot tetracosactrin and one dose of corticotrophin gel. During the course of the trial three dose levels of tetracosactrin were used: $1,0.5$, and $0.25 \mathrm{mg}$. Corticotrophin gel was assessed at twodose levels: 50 and 25 units. Half the patients received tetracosactrin on Day 2 and corticotrophin gel on Day 5. The remaining patients received their injections in the reverse order. Plasma 11-OHCS (Mattingly, 1962) were determined in each

TABBLE I.-Plasma 11-OHCS Expressed as $\mu g . / 100 \mathrm{ml}$. Related to Time of Day. Corticotrophin (A.C.T.H.) was Administered at 9 a.m. on Day 2 and Day 5

\begin{tabular}{|c|c|c|c|c|c|c|c|c|c|c|c|c|c|c|c|c|c|c|}
\hline \multirow{3}{*}{$\begin{array}{l}\text { Case } \\
\text { No. }\end{array}$} & \multirow{3}{*}{ Age } & \multirow{3}{*}{ Sex } & \multirow{3}{*}{$\begin{array}{l}\text { Day } 1 \\
9 \text { a.m. }\end{array}$} & \multicolumn{6}{|c|}{ Day 2} & \multirow{3}{*}{$\begin{array}{l}\text { Day } 3 \\
9 \text { a.m. }\end{array}$} & \multirow{3}{*}{$\begin{array}{l}\text { Day } 4 \\
9 \text { a.m. }\end{array}$} & \multicolumn{6}{|c|}{ Day 5} & \multirow{3}{*}{$\begin{array}{l}\text { Day } 6 \\
9 \text { a.m. }\end{array}$} \\
\hline & & & & \multicolumn{2}{|c|}{ A.C.T.H. } & \multirow{2}{*}{9 a.m. } & \multirow{2}{*}{1 p.m. } & \multirow{2}{*}{5 p.m. } & \multirow{2}{*}{9 p.m. } & & & \multicolumn{2}{|c|}{ А.C.Т.H. } & \multirow{2}{*}{9 a.m. } & \multirow{2}{*}{1 p.m. } & \multirow{2}{*}{5 p.m. } & \multirow{2}{*}{9 p.m. } & \\
\hline & & & & Type & Dose & & & & & & & Type & Dose & & & & & \\
\hline $\begin{array}{r}1 \\
2 \\
3 \\
4 \\
5 \\
6 \\
7 \\
8 \\
9 \\
10 \\
11 \\
12\end{array}$ & $\begin{array}{l}56 \\
68 \\
45 \\
54 \\
50 \\
52 \\
61 \\
68 \\
54 \\
60 \\
76 \\
50\end{array}$ & $\begin{array}{c}\text { M } \\
\mathbf{F} \\
\mathbf{M} \\
\mathbf{M} \\
\mathbf{F} \\
\mathbf{F} \\
\mathbf{F} \\
\mathbf{F} \\
\underset{F}{F} \\
\mathbf{M}\end{array}$ & $\begin{array}{l}16 \\
19 \\
17 \cdot 5 \\
6.5 \\
9.5 \\
15 \\
7 \\
2 \\
7 \\
17.5 \\
21.5 \\
21\end{array}$ & $\begin{array}{l}\text { TCA } \\
\text { TCA } \\
\text { TCA } \\
\text { TCA } \\
\text { TCA } \\
\text { TCA } \\
\text { Gel } \\
\text { Gel } \\
\text { Gel } \\
\text { Gel } \\
\text { Gel } \\
\text { Gel }\end{array}$ & $\begin{array}{c}1 \mathrm{mg} . \\
1 \mathrm{mg} \\
0.5 \mathrm{mg} . \\
0.5 \mathrm{mg} . \\
0.25 \mathrm{mg} . \\
0.25 \mathrm{mg} . \\
25 \text { units } \\
50 \text { units } \\
25 \text { units } \\
50 \text { units } \\
25 \text { units } \\
50 \text { units }\end{array}$ & $\begin{array}{c}18 \\
20 \\
18 \\
6 \\
31 \\
19 \cdot 5 \\
17 \cdot 5 \\
2 \\
9 \\
23 \cdot 5 \\
13 \\
27\end{array}$ & $\begin{array}{l}76 \cdot 8 \\
72 \\
38 \cdot 5 \\
78 \\
59 \\
55 \\
77 \cdot 5 \\
55 \cdot 5 \\
70 \\
63 \\
50 \\
66 \cdot 5\end{array}$ & $\begin{array}{l}36 \\
95 \\
59 \cdot 5 \\
87 \\
62 \\
56 \\
85 \\
71 \\
40 \cdot 5 \\
79 \\
49 \\
40\end{array}$ & $\begin{array}{l}32 \cdot 5 \\
51 \\
89 \\
44 \cdot 5 \\
65 \\
67 \\
44 \cdot 5 \\
21 \cdot 5 \\
47 \\
32 \\
33 \cdot 5\end{array}$ & $\begin{array}{c}64 \\
64 \\
47 \\
90 \\
41 \\
54 \\
16 \\
2 \\
2 \\
14 \\
7 \cdot 5 \\
20\end{array}$ & $\begin{array}{c}53 \cdot 3 \\
9 \\
15 \\
24 \\
33 \\
20 \\
20 \\
8 \\
2 \\
26 \cdot 5 \\
24 \\
37\end{array}$ & $\begin{array}{l}\text { Gel } \\
\text { Gel } \\
\text { Gel } \\
\text { Gel } \\
\text { Gel } \\
\text { Gel } \\
\text { TCA } \\
\text { TCA } \\
\text { TCA } \\
\text { TCA } \\
\text { TCA } \\
\text { TCA }\end{array}$ & $\begin{array}{l}25 \text { units } \\
50 \text { units } \\
25 \text { units } \\
50 \text { units } \\
25 \text { units } \\
50 \text { units } \\
1 \mathrm{mg} . \\
1 \mathrm{mg} . \\
0.5 \mathrm{mg} . \\
0.5 \mathrm{mg} . \\
0.25 \mathrm{mg} . \\
0.25 \mathrm{mg} .\end{array}$ & $\begin{array}{l}16 \\
14 \\
19 \\
35 \\
37 \\
35 \\
26 \\
20 \\
2 \\
18 \cdot 5 \\
14 \\
31\end{array}$ & $\begin{array}{l}57 \\
41 \cdot 3 \\
44 \cdot 5 \\
71 \\
45 \\
52 \cdot 5 \\
96 \\
36 \\
43 \\
62 \\
70 \\
55\end{array}$ & $\begin{array}{l}66 \cdot 5 \\
44 \cdot 5 \\
34 \\
55 \\
47 \\
48 \\
93 \\
64 \\
45 \\
75 \\
81 \\
48\end{array}$ & $\begin{array}{c}35 \cdot 5 \\
28 \\
12 \\
53 \\
32 \\
20 \\
133 \\
52 \\
54 \\
67 \\
69 \\
81\end{array}$ & $\begin{array}{l}59 \cdot 5 \\
20 \cdot 5 \\
10 \\
25 \\
2 \\
120 \\
55 \\
49 \\
68 \cdot 5 \\
34 \\
49\end{array}$ \\
\hline
\end{tabular}

$\mathrm{TCA}=$ Depot tetracosactrin. $\mathrm{Gel}=$ Corticotrophin gel. 